\title{
Multilocus sequence phylogenetic study of the genus Haemophilus with description of Haemophilus pittmaniae sp. nov.
}

Correspondence

Niels Nørskov-Lauritsen norskov@microbiology.au.dk
Niels Nørskov-Lauritsen, ${ }^{1,2}$ Brita Bruun ${ }^{3}$ and Mogens Kilian²

\author{
'Department of Clinical Microbiology, Aarhus University Hospital, DK-8000 Aarhus, Denmark \\ ${ }^{2}$ Department of Medical Microbiology and Immunology, Aarhus University, DK-8000 Aarhus, \\ Denmark \\ ${ }^{3}$ Department of Clinical Microbiology, Hillerød Hospital, DK-3400 Hillerød, Denmark
}

\section{INTRODUCTION}

As delineation of the genus Haemophilus based on dependence on haemin (X-factor) or NAD (V-factor) has become obsolete, a major revision of the genus may be warranted. One strategy would be to adopt the hierarchical classification 'that reflects the phylogeny of prokaryotes, as defined by $16 \mathrm{~S}$ rRNA sequence analysis' (Garrity et al., 2003). If the Pasteurellaceae are to be divided into phylogenetically consistent monophyletic groups based on $16 \mathrm{~S}$

Published online ahead of print on 24 September 2004 as DOI 10.1099/ijs.0.63325-0.

Abbreviations: adk, adenylate kinase gene; infB, translation initiation factor 2 gene; pgi, glucose-6-phosphate isomerase gene; recA, recombinase A gene.

The GenBank/EMBL/DDBJ accession numbers for the sequences reported in this paper are AJ289631, AJ289636, AJ289639, AJ289640, AJ289644, AJ289650, AJ289653, AJ289659, AJ289664AJ289671, AJ289675, AJ289677, AJ289679-AJ289681, AJ289685, AJ289688, AJ289690, AJ289694, AJ290754, AJ290755, AJ290758, AJ295746, AJ438112, AJ585268-AJ585341, AY597040 and AY736136-AY736145.

A table showing the origins of human isolates of Haemophilus pittmaniae sp. nov. is available as supplementary material in IJSEM Online.
rRNA gene sequences, more than 20 genera will be needed to cover the family (Olsen et al., 2004). Nomenclatural changes along these lines have been initiated and new genera include Lonepinella (Osawa et al., 1995), Mannheimia (Angen et al., 1999), Phocoenobacter (Foster et al., 2000), Gallibacterium (Christensen et al., 2003), Histophilus (Angen et al., 2003) and Volucribacter (Christensen et al., 2004).

Fifteen named Haemophilus species are listed in the latest edition of Bergey's Manual of Systematic Bacteriology (Kilian, 2004). By $16 S$ rRNA gene sequence comparison, the family Pasteurellaceae is divided into 21 rRNA clusters with named Haemophilus species dispersed among 10 of them (Olsen et al., 2004). 'Haemophilus sensu stricto' (rRNA cluster 16) is composed of Haemophilus influenzae, Haemophilus aegyptius and Haemophilus haemolyticus, whereas the Aphrophilus cluster (13) encompasses Haemophilus aphrophilus, Haemophilus paraphrophilus and Haemophilus segnis, as well as Actinobacillus actinomycetemcomitans. Haemophilus parainfluenzae, Haemophilus parasuis, Haemophilus felis, Haemophilus paracuniculus, Haemophilus haemoglobinophilus and Haemophilus ducreyi are placed in separate clusters $(2,8,9,11,17$ and 19, respectively) and Haemophilus paragallinarum is grouped with other taxa isolated 
from birds in the Avian cluster (18). Haemophilus paraphrohaemolyticus is located in a so-called Porcine cluster (3), adjacent to the Parainfluenzae cluster (Olsen et al., 2004); Haemophilus parahaemolyticus belongs to the same cluster (see below).

Some caution should be exercised before a classification based solely on $16 \mathrm{~S}$ rRNA gene sequences is adopted. With respect to the genus Haemophilus, the problems are particularly related to $H$. parainfluenzae and to some extent to the parahaemolyticus group ( $H$. parahaemolyticus and $H$. paraphrohaemolyticus). For reasons of clarity, the term 'cluster' is reserved to denote Pasteurellaceae 16S rRNA gene sequence clusters as defined in the latest version of Bergey's Manual (Olsen et al., 2004). Comprehensive DNA-DNA hybridization studies have indicated a generic placement of $H$. parainfluenzae within the boundaries of the genus Haemophilus (Burbach, 1987; Mutters et al., 1989). DNADNA hybridization also indicates that the parahaemolyticus group takes up an intermediate position between 'Haemophilus sensu stricto' and other parts of the family Pasteurellaceae (Burbach, 1987). By investigating 66 isolates of Haemophilus and related bacteria, it has been shown previously that partial infB sequencing supports delineation of the genus Haemophilus obtained by DNA-DNA hybridization (Hedegaard et al., 2001).

The present study was undertaken to investigate further the structure of the genus Haemophilus by examining the phylogeny of three other housekeeping genes, the adenylate kinase gene $(a d k)$, the glucose-6-phosphate isomerase gene $(p g i)$ and the recombination protein gene $(\operatorname{rec} A)$. Apart from $H$. ducreyi, which is unrelated to $H$. influenzae by DNA-DNA hybridization (Casin et al., 1985) and only distantly related $(93.6 \%)$ by $16 \mathrm{~S}$ rRNA gene sequence analysis (Olsen et al., 2004), representatives of all Haemophilus species primarily associated with man were examined.

\section{METHODS}

Bacterial strains and phenotypic characterization. Sequences from 28 representatives of Haemophilus species and related bacteria were examined in the study: $H$. influenzae $\mathrm{HK} 389^{\mathrm{T}}, H$. aegyptius HK $367^{\mathrm{T}}$, H. haemolyticus HK $386^{\mathrm{T}}$ and HK 676 (=CCUG 49488), H. parainfluenzae HK 409 ${ }^{\mathrm{T}}$, HK 23 (=CCUG 49489), HK 102 (=CCUG 49490) and HK 755 (=CCUG 49491) (of biotypes I, II, III and V, respectively), a novel Haemophilus taxon (subcluster 2C in Hedegaard et al., 2001) HK $85^{\mathrm{T}}$ (=CCUG $\left.48703^{\mathrm{T}}\right)$, HK 847 (=CCUG 48704) and P1525 (=CCUG 48706), H. parahaemolyticus HK $385^{\mathrm{T}}$ and HIM 570-6 (=CCUG 49512), H. paraphrohaemolyticus HK $411^{\mathrm{T}}$ and P1300 (=CCUG 49492), Actinobacillus lignieresii $\mathrm{P} 151^{\mathrm{T}}$, Actinobacillus pleuropneumoniae ATCC $27088^{\mathrm{T}}$, H. aphrophilus $\mathrm{P}_{001} 1^{\mathrm{T}}$ and RH01 (=CCUG 49493), H. paraphrophilus HK $415^{\mathrm{T}}$ and HK 83 (=CCUG 49494), H. segnis HK 316 ${ }^{\mathrm{T}}$, HK 321 (=CCUG 49495) and HK 701 (=CCUG 18088), A. actinomycetemcomitans CCUG $13227^{\mathrm{T}}$ and HK 1651 (=CCUG 49496), and Pasteurella multocida $\mathrm{P} 801^{\mathrm{T}}$ and $\mathrm{Pm} 70$. Strains were selected from our previous study of infB sequences (Hedegaard et al., 2001) and supplemented with the type strain of $A$. lignieresii, the additional $H$. aphrophilus isolate (RH01) and Pm70, a fully sequenced isolate of P. multocida (May et al., 2001).
The origins of the nine isolates described as a novel species $(H$. pittmaniae sp. nov.) are listed in a table available as supplementary material in IJSEM Online. NAD dependence was assessed by V-factor tablets from Rosco Diagnostics placed on inoculated brain heart infusion agar plates. IgA1 protease activity was analysed as described previously (Kilian et al., 1979). Activities of proline arylamidase and $\gamma$-glutamyl transferase were tested with the API NH system (bioMérieux). Activities of acid and alkaline phosphatases plus leucine arylamidase were tested with API ZYM (bioMérieux). Other phenotypic tests were carried out as described previously (Kilian, 1976). Detection of adenylate kinase activity by multilocus enzyme electrophoresis was performed according to Selander et al. (1986). The biotypes of $H$. parainfluenzae were defined as described by Kilian (2003). Activity of $\beta$-lactamase was evaluated by a chromogenic assay (PCN; Becton-Dickinson).

DNA sequencing. Housekeeping genes $a d k$, pgi and $r e c A$ were selected from the multilocus sequence typing scheme of $H$. influenzae (Meats et al., 2003). The genes were identified in Escherichia coli (GenBank accession nos AE000153, X15196 and AE005498), $H$. influenzae Rd KW20 (NC_000907), P. multocida PM70 (AE004439) and $A$. actinomycetemcomitans HK 1651 [unfinished genome by the Actinobacillus Genome Sequencing Project (B. A. Roe, F. Z. Najar, A. Gillaspy, S. Clifton, T. Ducey, L. Lewis and D. W. Dyer) at http:// www.genome.ou.edu/act.html]. From alignments of the individual genes, the following degenerate primers were designed (nt numbering with reference to $E$. coli): $a d k .34 f, 5^{\prime}$-GGIAAAGGIACWCARGCICARTT; adk.610r, 5'-CTTCCACTTTTTKYGTMCCGTC; pgi.838f, 5'-GATGGIAAAGAYGTIATGCC; pgi.1331r, 5'-GCTGACCAYAAIGARTAACG; recA.54f, 5'-GARAAACAATTTGGKAAAGGC; and recA.617r, 5' -TTACCRAACATMACRCCIAT (I, deoxyinosine; W, A or T; R, G or A; K, G or T; Y, C or T; M, A or C). The primers cover approximately the same internal fragments of the genes as used in the multilocus sequence typing scheme of $H$. influenzae.

DNA was released from cells as previously described (Hedegaard et al., 2001) and $1 \mu$ was amplified in Ready-to-go vials (Pharmacia) with 15 pmol forward and $15 \mathrm{pmol}$ reverse primers in a total volume of $25 \mu \mathrm{l}$. After an initial denaturation step at $94^{\circ} \mathrm{C}$ for 5 min, 30 cycles $\left(94^{\circ} \mathrm{C}\right.$ for $1 \mathrm{~min}, 50^{\circ} \mathrm{C}$ for $1 \mathrm{~min}$ and $72^{\circ} \mathrm{C}$ for $2 \mathrm{~min}$ ) were run. Amplicons were purified on silica-gel columns (QIAquick PCR purification kit) and cycle sequenced from both ends using the PCR primers and a ThermoSequenase dye terminator sequencing kit (Pharmacia Biotech). Sequencing reactions were analysed on an ABI 377 DNA sequencer.

Near-full-length 16S rRNA gene sequences were amplified with the primers (numbering with reference to $E$. coli, sequence accession number J01695) 16S.8f (5'-AGAGTTTGATYMTGGCT; Angen et al., 1999) and 16S.1513r (5'-TACGGYTACCTTGTTACGACT; Dewhirst et al., 1989). Purified products were sequenced as described above using the PCR primers and the internal primers described by Paster \& Dewhirst (1988) and Dewhirst et al. (1989). Fragments of 14501454 bp (corresponding to nt 25-1478 of E. coli 16S rRNA) were used for phylogenetic analysis.

Sequences were aligned as described previously (Nørskov-Lauritsen et al., 2004). Phylogenetic analysis and construction of dendrograms were carried out using MEGA version 2.1 (Kumar et al., 2001).

DNA-DNA hybridization. DNA was isolated using a French pressure cell (ThermoSpectronic) and was purified by chromatography on hydroxyapatite as described by Cashion et al. (1977). DNA-DNA hybridization was carried out at the Deutsche Sammlung von Mikroorganismen und Zellkulturen Gmbh, Braunschweig, Germany, as described by De Ley et al. (1970), with the modifications described by Huß et al. (1983) and Escara \& Hutton (1980), using a model 2600 spectrophotometer equipped with a model 2527-R 
thermoprogrammer and plotter (Gilford Instrument Laboratories). Renaturation rates were computed with the TRANSFER.BAS program of Jahnke (1992).

\section{RESULTS}

\section{Comparison of individual housekeeping gene fragments}

The relationship of the study strains based on comparison of adk sequences showed a core group of Haemophilus encircling the influenzae group ( $H$. influenzae, H. aegyptius and $H$. haemolyticus), the heterogeneous species $H$. parainfluenzae and the novel taxon $H$. pittmaniae sp. nov. (Fig. 1b). These species were more related to strains of both Pasteurella and Actinobacillus sensu stricto than to the Aphrophilus cluster (Fig. 1b and Table 1). It was not possible to amplify an adk fragment in isolates of the parahaemolyticus group and these four strains are not included in the neighbour-joining dendrogram based on adk sequences. The type strain of $H$. parahaemolyticus contains detectable adenylate kinase activity, as evaluated

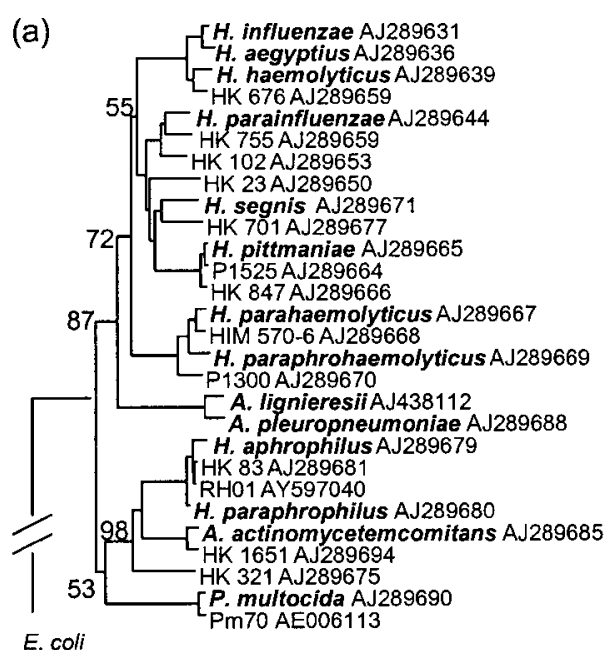

(c)

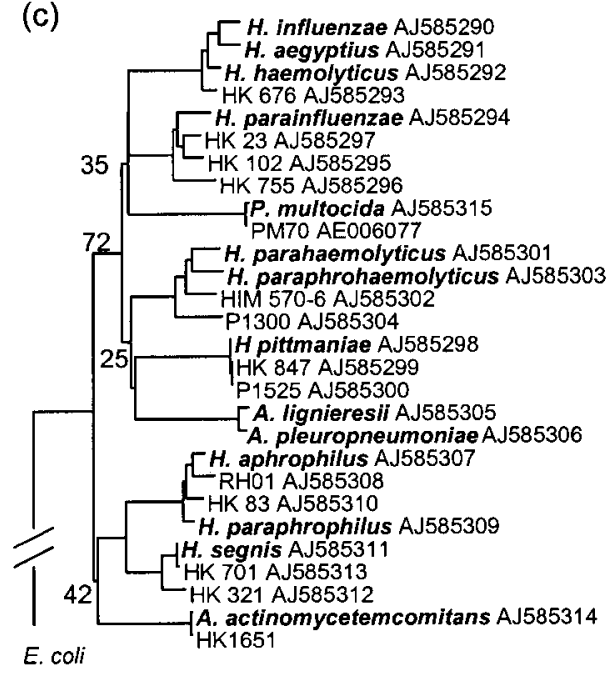

(b)
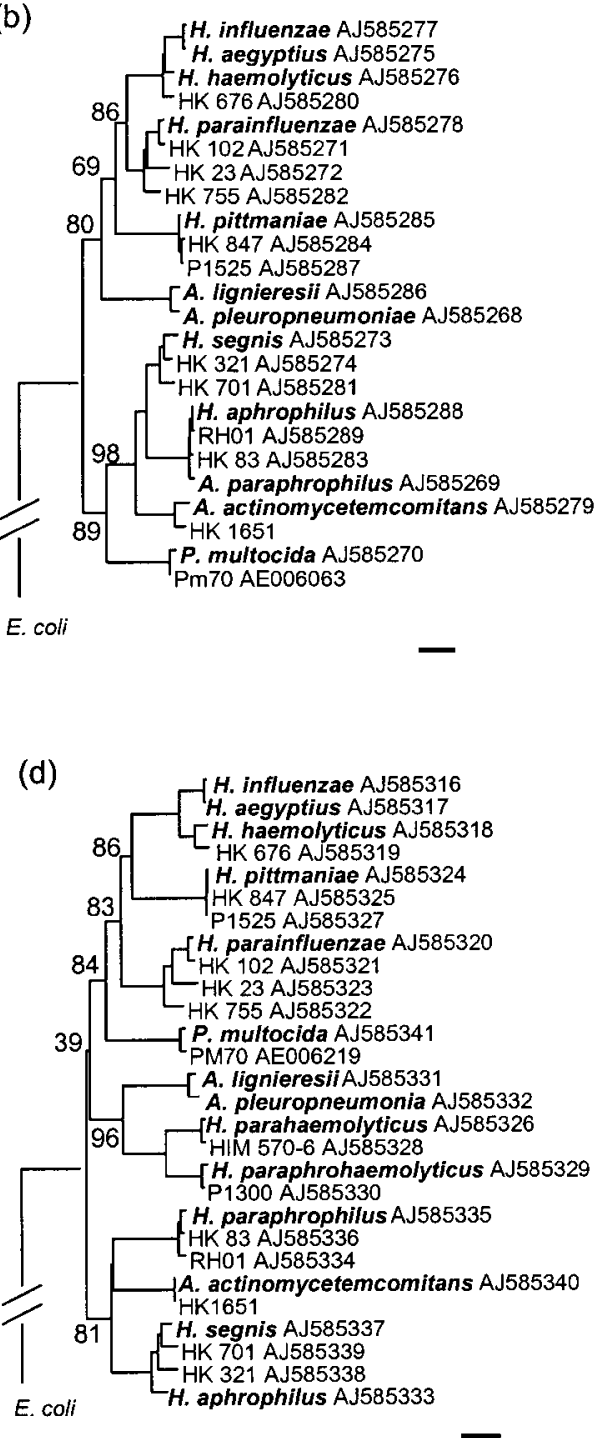

Fig. 1. Neighbour-joining dendrograms based on partial sequences of separate housekeeping genes. Type strains are emphasized in bold. Nucleotide sequence accession numbers are given, except for HK 1651, for which no sequence accession numbers are yet available (see Methods). Evolutionary distances are given in terms of the number of base substitutions weighted by the Kimura two-parameter model. Values to the left of nodes are bootstrap replications (\%) supporting the node. Bars, 5 substitutions per 100 nt. (a) Translation initiation factor 2 gene, infB (453 nt); (b) adenylate kinase gene, adk (453 nt); (c) glucose-6-phosphate isomerase gene, pgi (393 nt); and (d) recombinase $A$ gene, rec $A$ (447 nt). 
Table 1. Sequence similarity (\%) of four housekeeping gene fragments of the type strain of $H$. influenzae with selected groups of Pasteurellaceae

\begin{tabular}{|lcccc|}
\hline Sequence group (number of strains) & \multicolumn{4}{c|}{ Gene fragment } \\
\cline { 2 - 5 } & infB & adk & pgi & recA \\
\hline H. aegyptius, H. haemolyticus (3) & $95-98$ & $95-99$ & $93-95$ & $93-99$ \\
H. parainfluenzae (4) & $87-89$ & $86-88$ & $78-80$ & $81-82$ \\
H. pittmaniae sp. nov. (3) & 87 & 81 & 74 & 81 \\
Parahaemolyticus group (4) & $85-86$ & $\mathrm{ND}$ & $79-81$ & $72-74$ \\
A. lignieresii, A. pleuropneumoniae (2) & 81 & $79-80$ & 75 & $71-72$ \\
P. multocida (2) & $79-80$ & $76-77$ & 77 & $77-78$ \\
Aphrophilus cluster (9) & $79-82$ & $73-76$ & $69-74$ & $75-76$ \\
E. coli (1) & 65 & 60 & 73 & 63 \\
\hline
\end{tabular}

ND, Not determined.

by multilocus enzyme electrophoresis (result not shown), and the failure of the amplification must be ascribed to a primer mismatch.

The relationship inferred from an alignment of pgi sequences was somewhat different (Fig. 1c). The sequence carried by $E$. coli was sufficiently unique to place this species as an outgroup, despite the larger number of nucleotide substitutions observed between $H$. influenzae and some members of the Aphrophilus cluster than between $H$. influenzae and E. coli (Table 1). The Aphrophilus cluster ( $H$. aphrophilus, $H$. paraphrophilus, $H$. segnis and $A$. actinomycetemcomitans) was located on a separate and distant branch, which is similar to the phylogeny inferred from the other housekeeping genes. However, the rest of the sequence groups, including representatives of Pasteurella and Actinobacillus, showed similarity with $H$. influenzae at a level of 75-80\% (Table 1) and appeared to branch at equal depths in the dendrogram (Fig. 1c). Only moderate bootstrap values supported the new constellation of sequence groups.

Using recA sequence comparisons, the outline of the family inferred from infB and $a d k$ analysis was recognized. However, the $P$. multocida strains were more closely related to the influenzae group using $r e c A$ than they were using infB and $a d k$ sequences (Table 1) and took up a different position in the dendrogram. The type strain of $H$. aphrophilus (accession no. AJ585333) clustered with $H$. segnis rather than with the other representatives of $H$. aphrophilus and $H$. paraphrophilus; the recA locus of this strain has most likely been subject to a recombination event (Fig. 1d).

Relationships based on infB sequences from our previous investigation (Hedegaard et al., 2001) are shown (Fig. 1a) for comparison with those for the other housekeeping genes. The outline of the family inferred from $a d k$ and recA sequence comparison is supported by infB analysis. However, the three strains of $H$. segnis are in two separate groups, probably because of a recombination event affecting the ancestor of the type strain and strain HK 701.

\section{Multilocus phylogeny}

The sequenced fragments of the separate housekeeping genes from each strain were joined together and phylogenetic analysis was performed. The concatenated sequence comprised $1746 \mathrm{nt}$ for most of the strains, but only $1293 \mathrm{nt}$ for representatives of the parahaemolyticus group, because of the lack of $a d k$ sequences. For E. coli and P. multocida, a triplet deletion in $\inf B$ resulted in a concatenated sequence of $1743 \mathrm{nt}$. A dendrogram constructed by the neighbourjoining method is shown in Fig. 2(a). The three representatives of $H$. segnis coalesced into a single group, although the aberrant result of infB sequencing was discernible in the dendrogram and in the moderate bootstrap value of $79 \%$ (Fig. 2a). Also, the type strain of H. aphrophilus was located next to its kin, despite the atypical recA sequence.

Based on a multilocus sequence comparison of the investigated taxa, $H$. parainfluenzae and $H$. pittmaniae sp. nov. are the species most closely related to the influenzae group ( $H$. influenzae, $H$. aegyptius and $H$. haemolyticus). The Aphrophilus cluster is as separate from the type species of the genus Haemophilus as are the type species of Actinobacillus and Pasteurella. Multilocus sequence phylogenetic analysis could not support conservation of the parahaemolyticus group within the genus 'Haemophilus sensu stricto' (Fig. 2a), although this comparison is restricted to three genes.

Fig. 2(b) shows the phylogenetic comparison based on near-full-length 16S rRNA gene sequences. The 16S rRNA gene sequence of the type strain of $H$. parahaemolyticus, available in databases as M75073, is based on an incorrect strain (Hedegaard et al., 2001) and therefore both the type strain $\left(\mathrm{HK} 385^{\mathrm{T}}\right)$ and H. parahaemolyticus strain HIM 570-6 (sequence accession nos AJ295746 and AJ290758, respectively) were sequenced. The $1466 \mathrm{nt} 16 \mathrm{~S}$ rRNA gene sequence of HK $385^{\mathrm{T}}$ determined by us showed $96 \%$ similarity with the deposited sequence of the type strain of H. paraphrohaemolyticus (M75076). However, it showed $99 \%$ similarity with strain MCCM 00189 (AF224283), 


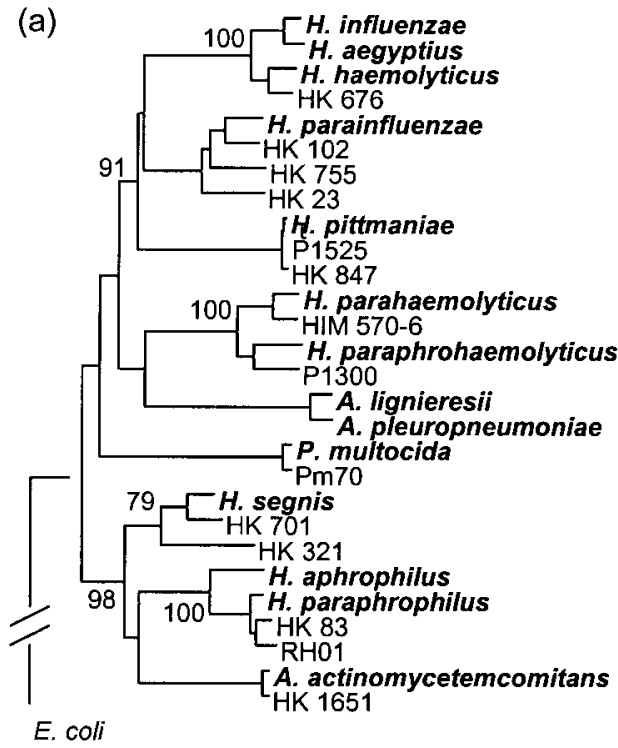

0.05

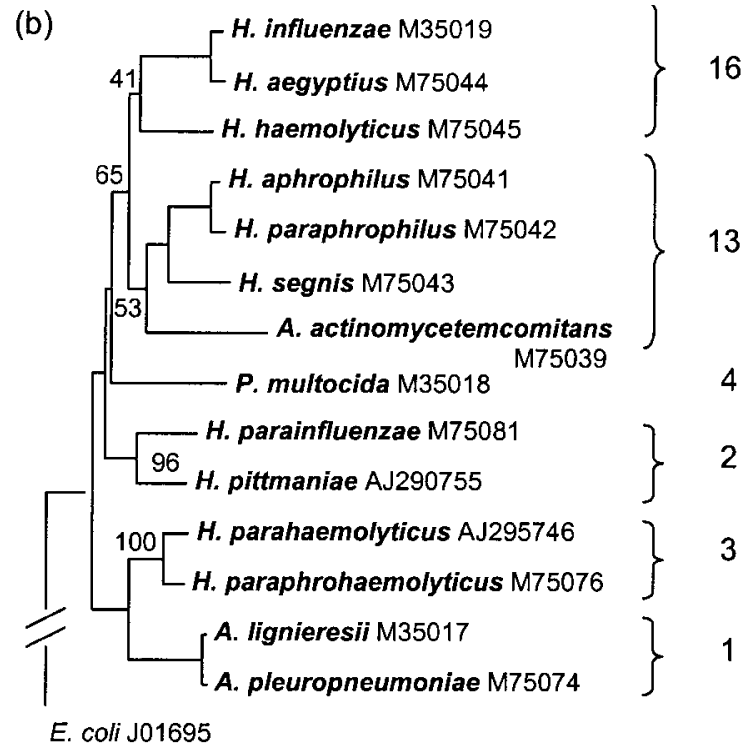

$\overline{0.01}$

Fig. 2. (a) Neighbour-joining tree based on concatenated sequences from the four separate housekeeping genes infB, adk, pgi and recA (1746 nt, except for the parahaemolyticus group, where adk was not amplified resulting in a total of $1293 \mathrm{nt})$. Bar, 5 substitutions per $100 \mathrm{nt}$ (weighted by the Kimura two-parameter model). (b) Neighbour-joining tree based on 1450-1454 nt 16S rRNA gene sequences from type strains. Nucleotide sequence accession numbers are given. Bar, 1 substitution per $100 \mathrm{nt}$ (calculation performed with even-weighted characters ignoring gaps and ambiguous positions). Brackets delineate numbered 16S rRNA gene clusters of Olsen et al. (2004).

classified as Actinobacillus pleuropneumoniae, which is in the Porcine cluster of the Pasteurellaceae according to Olsen et al. (2004). This level of similarity (99\%; 1456/1466 nt) is also seen between HK $385^{\mathrm{T}}$ and strain HIM 570-6 and suggests incorrect identification of strain MCCM 00189.

The phylogeny of the 16S rRNA gene in the family Pasteurellaceae (Olsen et al., 2004) is shown in Fig. 2(b), with the Aphrophilus cluster (13) being most closely related to 'Haemophilus sensu stricto' (rRNA cluster 16) and H. parainfluenzae taking up a more distant position in the dendrogram. The $1468 \mathrm{nt} 16 \mathrm{~S}$ rRNA gene sequence of strain HK $85^{\mathrm{T}}$ (type strain of $H$. pittmaniae sp. nov.) showed $95 \%$ similarity with the type strain of $H$. parainfluenzae and was located in the Parainfluenzae cluster (2).

\section{DNA-DNA hybridization and homogeneity of the novel taxon}

DNA-DNA hybridization experiments were performed to disclose further the position of the novel taxon. The DNA relatedness between strain $\mathrm{HK} 85^{\mathrm{T}}$ and strain HK 847 was $\sim 80 \%$, which is well above the threshold value of $70 \%$ that has been suggested for the definition of bacterial species (Wayne et al., 1987). Of the type strains tested, HK $85^{\mathrm{T}}$ was most closely related to $H$. parainfluenzae (Table 2 ).

Nine isolates of $H$. pittmaniae sp. nov. were available for investigation. The species appeared relatively homogeneous, with an infB sequence similarity in excess of $97 \%$ (based on $453 \mathrm{nt}$ ) and a $16 \mathrm{~S}$ rRNA gene sequence similarity in excess of $99 \%$ (380 nt) (alignments not shown; see supplementary material available in IJSEM Online regarding strain origin and individual nucleotide sequence accession numbers). Phenotypic characteristics are given in the species description.

Near-full-length 16S rRNA gene sequences of $H$. pittmaniae strains $\mathrm{HK} 85^{\mathrm{T}}$ and $\mathrm{P} 1525$ have been deposited under accession numbers AJ290755 and AJ290754, respectively.

Table 2. DNA-DNA relatedness between $H$. pittmaniae sp. nov. HK $85^{\top}$ and selected strains of the Pasteurellaceae

\begin{tabular}{|lc|}
\hline Strain & DNA-DNA relatedness (\%) \\
\hline H. pittmaniae $\mathrm{HK} 847$ & $80 \pm 3^{*}$ \\
A. lignieresii $\mathrm{P} 151^{\mathrm{T}}$ & 22 \\
P. multocida $\mathrm{P} 427^{\mathrm{T}}$ & 22 \\
H. aphrophilus $\mathrm{HK} 372^{\mathrm{T}}$ & 19 \\
H. parahaemolyticus $\mathrm{HK} 385^{\mathrm{T}}$ & 22 \\
H. influenzae $\mathrm{HK} 389^{\mathrm{T}}$ & 29 \\
H. parainfluenzae $\mathrm{HK} 409^{\mathrm{T}}$ & 34 \\
\hline
\end{tabular}

${ }^{\star}$ Mean $\pm \mathrm{SD}$ of two experiments. 


\section{DISCUSSION}

The degenerate primers employed for partial sequencing of the four housekeeping genes were able to recognize the target genes in the 28 study strains, except for the four representatives of the parahaemolyticus group, where a probable mismatch prevented successful amplification of the adk gene fragment. A total of 108 gene fragments was thus available for analysis.

The sequences obtained were divided into separate and distinct sequence groups. The grouping of sequences followed speciation of the strains with few exceptions. As previously shown for $H$. segnis, the infB gene fragment in this species can belong to either of two separate sequence groups (Hedegaard et al., 2001). An aberrant result was obtained with the recA gene fragment of $H$. aphrophilus $\mathrm{P}_{80} 1^{\mathrm{T}}$, which was related to the sequences obtained from representatives of $H$. segnis rather than $H$. aphrophilus and $H$. paraphrophilus (Fig. 1d). In all other cases, the grouping of sequences was in accordance with speciation of the strains, although some sequence groups enclosed more than one species.

The Haemophilus species isolated from man and dependent on both the $\mathrm{X}$ - and $\mathrm{V}$-factor (the influenzae group: $H$. influenzae, $H$. aegyptius and $H$. haemolyticus) are closely related. In fact, the differences between four representatives of the species $H$. parainfluenzae were larger than those between four representatives of the three species in the influenzae group (Fig. 2a; calculation not shown). The close relationship of the species of the influenzae group is supported by DNA-DNA hybridization data (Burbach, 1987; Casin et al., 1986) and 16S rRNA gene sequence similarity analysis (Olsen et al., 2004).

The interrelationship between A. actinomycetemcomitans, $H$. aphrophilus, $H$. paraphrophilus and $H$. segnis has previously been demonstrated by DNA-DNA hybridization (Potts et al., 1986), rRNA gene sequence analysis (Olsen et al., 2004) and infB sequence comparison (Hedegaard et al., 2001). The vicinal position of these species was emphasized by the sequence similarities of three additional housekeeping gene fragments analysed in this study. A controversy, however, exists about the generic placement of the group. A proposed transfer of A. actinomycetemcomitans to the genus Haemophilus (Potts et al., 1985) is not supported due to the low level of relatedness with the type species (Kilian, 2004). Early comparisons of $16 \mathrm{~S}$ rRNA gene sequences in the family Pasteurellaceae placed $A$. actinomycetemcomitans, $H$. aphrophilus, $H$. paraphrophilus and $H$. segnis together with $H$. influenzae (Dewhirst et al., 1992). However, after inclusion of 114 16S rRNA gene sequences, this delineation of the genus Haemophilus was found to be polyphyletic and separate clusters were created for 'Haemophilus sensu stricto' (rRNA cluster 16) and the Aphrophilus cluster (13) (Olsen et al., 2004). Results from the housekeeping gene sequencing are unequivocal. The sequences carried by members of the Aphrophilus cluster are quite different from those of the influenzae group in all four gene loci (Fig. 1). In the comparison of the concatenated sequences, representatives of the Aphrophilus cluster were less related to $H$. influenzae than to any of the other investigated taxa, including type species of the genera Pasteurella and Actinobacillus (Fig. 2). Consequently, species of the Aphrophilus cluster do not belong to the genus Haemophilus.

The specific status and generic placement of the parahaemolyticus group $(H$. parahaemolyticus and $H$. paraphrohaemolyticus) have also been a subject of discussion. Kilian (1976) questioned the specific assignment of $H$. parahaemolyticus on the basis of an extended phenotypic investigation. The only characteristic that distinguished this species from biotype III of $H$. parainfluenzae was haemolytic activity and this was considered unstable. Results of DNA-DNA hybridization experiments, however, verified the specific status of the parahaemolyticus group, although the separation into two species was not investigated in detail (Burbach, 1987). Further differentiating phenotypic characters have been searched for, and fermentation of mannose, production of $\beta$-galactosidase and the presence of IgA1 protease have been shown to differentiate $H$. parainfluenzae, $H$. parahaemolyticus and $H$. paraphrohaemolyticus (Kilian, 2004).

The confused identity of strains subjected to $16 \mathrm{~S}$ rRNA gene sequencing has complicated the issue. In the comprehensive comparison of $16 \mathrm{~S}$ rRNA gene sequences by Olsen et al. (2004), H. parahaemolyticus is included in Actinobacillus sensu stricto, whereas $H$. paraphrohaemolyticus is located in the so-called Porcine cluster (rRNA cluster 3), together with a strain (MCCM 00189) labelled A. pleuropneumoniae and two strains of Actinobacillus minor. However, as mentioned above, the 16S rRNA gene sequence of the type strain of $H$. parahaemolyticus available in the databases as M75073 is not based on the correct strain (Hedegaard et al., 2001). The 16S rRNA gene sequence of the type strain of $H$. parahaemolyticus determined in this study showed $96 \%$ similarity to the type strain of $H$. paraphrohaemolyticus (accession no. M75076); this difference supports the existence of separate species in the parahaemolyticus group. Moreover, the 16S rRNA gene sequence of the two representatives of $H$. parahaemolyticus determined in this study showed $99 \%$ similarity to that of strain MCCM 00189 (accession no. AF224283) of 16S rRNA cluster 3. This suggests that accession number AF224283 represents an isolate of $H$. parahaemolyticus and that the so-called Porcine cluster (rRNA cluster 3) of Olsen et al. (2004) is composed mainly of human bacterial species.

In addition to their different growth factor requirements, $H$. influenzae and $H$. parainfluenzae differ in their ability to ferment a number of carbohydrates (Kilian, 1976). Results from DNA-DNA hybridization studies, however, support placement of $H$. parainfluenzae in the genus Haemophilus (Burbach, 1987; Mutters et al., 1989). It was therefore unexpected when a markedly different phylogeny was 
inferred from 16S rRNA gene sequence analysis. In the initial report on 54 representative strains of species in the family Pasteurellaceae, $H$. parainfluenzae was located as an outgroup to the entire family (Dewhirst et al., 1992). In the study by Olsen et al. (2004), the Parainfluenzae cluster (encompassing the species $H$. parainfluenzae only) has been included as one of 21 clusters in the family, but at a position quite distant from 'Haemophilus sensu stricto'. With respect to housekeeping gene similarity, the heterogeneous group of $H$. parainfluenzae is related to $H$. influenzae, the type species of the genus Haemophilus. When a phylogenetic tree was constructed on the basis of a concatenated sequence of four genes, $H$. parainfluenzae, $H$. pittmaniae sp. nov. and the influenzae group constituted a monophyletic lineage supported by a bootstrap value of $91 \%$ (Fig. 2).

The novel taxon demonstrated in this study is sufficiently distinct from all named taxa by analysis of sequences of $16 \mathrm{~S}$ rRNA and selected housekeeping genes, DNA-DNA hybridization and phenotypic traits to warrant specific recognition. The spectrum of sugars used was similar to that observed for $H$. parainfluenzae, but the novel taxon was negative in the tests used for biotyping $H$. parainfluenzae (production of indole, urease and ornithine decarboxylase). Strains of $H$. parainfluenzae that are negative in the three biotyping tests have recently been demonstrated (biotype V; Hedegaard et al., 2001). The presence of haemolytic activity serves to discriminate the novel taxon from $H$. parainfluenzae biotype V. Haemolytic activity has been described for some isolates of $H$. parainfluenzae biotype II and IV (Hedegaard et al., 2001; Kilian, 2003). Negative reactions in the tests used for biotyping $H$. parainfluenzae are characteristic of both $H$. paraphrophilus and H. segnis. Apart from the lack of haemolysis, the former can be differentiated from the novel taxon by its ability to produce acid from lactose, the latter by its weak fermentative capability.

The questionable generic affiliation of $H$. parainfluenzae affects the naming of the novel taxon. It is most closely related to $H$. parainfluenzae by phenotype, comparison of both 16S rRNA and housekeeping gene sequences (Figs 1 and 2) and DNA-DNA hybridization data (Table 2). It is considered that removal of $H$. parainfluenzae from the genus Haemophilus cannot be supported by the available data and it is proposed that the novel taxon be maintained in the genus Haemophilus as H. pittmaniae sp. nov.

\section{Description of Haemophilus pittmaniae sp. nov.}

Haemophilus pittmaniae (pitt.ma'ni.ae. N.L. gen. fem. n. pittmaniae of Pittman, named in honour of Margaret Pittman for her substantial contributions to Haemophilus research).

Non-motile, facultatively anaerobic, Gram-negative, small, pleomorphic rods, with occasional long, filamentous forms. Colonies on chocolate agar are greyish white and reach a diameter of $1-2 \mathrm{~mm}$ after $24 \mathrm{~h}$ at $35^{\circ} \mathrm{C}$. A distinct $\beta$ haemolytic zone is produced around the colonies on horse or sheep blood agar. Depends on V-factor for growth on brain heart infusion agar plates, but is capable of growth on blood plates due to release of V-factor from lysed blood cells. Positive in the porphyrin test, negative or weakly positive in catalase and oxidase tests. Negative in the indole and urease tests. Acid is produced from D-glucose, Dfructose, sucrose, D-mannose, D-galactose and maltose. A small amount of gas is produced from glucose. Acid is not produced from lactose, D-xylose, D-mannitol, D-sorbitol, sorbose, melibiose, inulin, aesculin or amygdalin. Negative in lysine and ornithine decarboxylase and arginine dihydrolase tests. Negative for IgA1 protease. Produces $\beta$-galactosidase (ONPG), alkaline phosphatase, acid phosphatase and leucine arylamidase, but not $\beta$-glucosidase (NPG), $\alpha$-glucosidase (PNPG), $\beta$-glucosaminidase (GNAC), $\beta$-glucuronidase (PGUA) or $\alpha$-fucosidase (ONPF). Of the nine strains analysed, six are positive for $\gamma$-glutamyl transferase (GGT) activity and one is positive for $\beta$ lactamase activity.

The type strain is $\mathrm{HK} 85^{\mathrm{T}}$ (=CCUG $48703^{\mathrm{T}}=\mathrm{NCTC}$ $13334^{\mathrm{T}}$ ), isolated from human saliva. The species is part of the normal flora of the oral mucous membranes of man. It is an opportunistic pathogen and has been isolated from various sites of infection, including blood and bile.

\section{ACKNOWLEDGEMENTS}

Professor Dr Hans G. Trüper is thanked for etymological assistance. Our sequencing facility was a donation from the Velux Foundation.

\section{REFERENCES}

Angen, Ø., Mutters, R., Caugant, D. A., Olsen, J. E. \& Bisgaard, M. (1999). Taxonomic relationships of the [Pasteurella] haemolytica complex as evaluated by DNA-DNA hybridizations and 16S rRNA sequencing with proposal of Mannheimia haemolytica gen. nov., comb nov., Mannheimia granulomatis comb. nov., Mannheimia glucosida spec. nov., Mannheimia ruminalis sp. nov. and Mannheimia varigena sp. nov. Int J Syst Bacteriol 49, 67-86.

Angen, Ø., Ahrens, P., Kuhnert, P., Christensen, H. \& Mutters, R. (2003). Proposal of Histophilus somni gen. nov., sp. nov. for the three species incertae sedis 'Haemophilus somnus', 'Haemophilus agni and 'Histophilus ovis'. Int J Syst Evol Microbiol 53, 1449-1456.

Burbach, S. (1987). Reklassifizierung der Gattung Haemophilus Winslow et al. 1917 auf Grund der DNA-Basensequenzhomologie. PhD dissertation, Philipps-Universität Marburg, Germany.

Cashion, P., Holder-Franklin, M. A., McCully, J. \& Franklin, M. (1977). A rapid method for the base ratio determination of bacterial DNA. Anal Biochem 81, 461-466.

Casin, I., Grimont, F., Grimont, P. A. D. \& Sanson-Le Pors, M. J. (1985). Lack of deoxyribonucleic acid relatedness between Haemophilus ducreyi and other Haemophilus species. Int J Syst Bacteriol 35, 23-25.

Casin, I., Grimont, F. \& Grimont, P. A. (1986). Deoxyribonucleic acid relatedness between Haemophilus aegyptius and Haemophilus influenzae. Ann Inst Pasteur Microbiol 137B, 155-163. 
Christensen, H., Bisgaard, M., Bojesen, A. M., Mutters, R. \& Olsen, J. E. (2003). Genetic relationships among avian isolates classified as Pasteurella haemolytica, 'Actinobacillus salpingitidis' or Pasteurella anatis with proposal of Gallibacterium anatis gen. nov., comb. nov. and description of additional genomospecies within Gallibacterium gen. nov. Int J Syst Evol Microbiol 53, 275-287.

Christensen, H., Bisgaard, M., Aalbaek, B. \& Olsen, J. E. (2004). Reclassification of Bisgaard taxon 33, with proposal of Volucribacter psittacicida gen. nov., sp. nov. and Volucribacter amazonae sp. nov. as new members of the Pasteurellaceae. Int J Syst Evol Microbiol 54, 813-818.

De Ley, J., Cattoir, H. \& Reynaerts, A. (1970). The quantitative measurement of DNA hybridization from renaturation rates. Eur J Biochem 12, 143-153.

Dewhirst, F. E., Paster, B. J. \& Bright, P. L. (1989). Chromobacterium, Eikenella, Kingella, Neisseria, Simonsiella, and Vitreoscilla species comprise a major branch of the beta group Proteobacteria by $16 \mathrm{~S}$ ribosomal ribonucleic acid sequence comparison: transfer of Eikenella and Simonsiella to the family Neisseriaceae (emend.). Int J Syst Bacteriol 39, 258-266.

Dewhirst, F. E., Paster, B. J., Olsen, I. \& Fraser, G. J. (1992). Phylogeny of 54 representative strains of species in the family Pasteurellaceae as determined by comparison of $16 \mathrm{~S}$ rRNA sequences. J Bacteriol 174, 2002-2013.

Escara, J. F. \& Hutton, J. R. (1980). Thermal stability and renaturation of DNA in dimethyl sulfoxide solutions: acceleration of the renaturation rate. Biopolymers 19, 1315-1327.

Foster, G., Ross, H. M., Malnick, H., Willems, A., Hutson, R. A., Reid, R. J. \& Collins, M. D. (2000). Phocoenobacter uteri gen. nov., sp. nov., a new member of the family Pasteurellaceae Pohl (1979) 1981 isolated from a harbour porpoise (Phocoena phocoena). Int J Syst Evol Microbiol 50, 135-139.

Garrity, G. M., Bell, J. A. \& Lilburn, T. G. (2003). Taxonomic outline of the procaryotes. In Bergey's Manual of Systematic Bacteriology, 2nd edn, release 4.0, pp. 1-3. New York: Springer. doi:10.1007/ bergeysoutline 200310

Hedegaard, J., Okkels, H., Bruun, B., Kilian, M., Mortensen, K. K. \& Nørskov-Lauritsen, N. (2001). Phylogeny of the genus Haemophilus as determined by comparison of partial infB sequences. Microbiology 147, 2599-2609.

Huß, V. A. R., Festl, H. \& Schleifer, K. H. (1983). Studies on the spectrophotometric determination of DNA hybridization from renaturation rates. Syst Appl Microbiol 4, 184-192.

Jahnke, K. D. (1992). Basic computer program for evaluation of spectroscopic DNA renaturation data from GILFORD System 2600 spectrometer on a PC/XT/AT type personal computer. J Microbiol Methods 15, 61-73.

Kilian, M. (1976). A taxonomic study of the genus Haemophilus, with the proposal of a new species. J Gen Microbiol 93, 9-62.

Kilian, M. (2003). Haemophilus. In Manual of Clinical Microbiology, 8th edn, pp. 623-635. Edited by P. R. Murray, E. J. Baron, J. H. Jorgensen, M. A. Pfaller \& R. H. Yolken. Washington, DC: American Society for Microbiology.
Kilian, M. (2004). Genus Haemophilus Winslow, Broadhurst, Buchanan, Rogers and Smith 1917, 561 ${ }^{\mathrm{AL}}$. In Bergey's Manual of Systematic Bacteriology, 2nd edn. Edited by D. J. Brenner, N. R. Krieg, J. T. Staley \& G. M. Garrity. New York: Springer (in press). Kilian, M., Mestecky, J. \& Schrohenloher, R. E. (1979). Pathogenic species of Haemophilus and Streptococcus pneumoniae produce immunoglobulin A1 protease. Infect Immun 26, 143-149.

Kumar, S., Tamura, K., Jakobsen, I. B. \& Nei, M. (2001). MEGA2: molecular evolutionary genetics analysis software. Bioinformatics 17, 1244-1245.

May, B. J., Zhang, Q., Li, L. L., Paustian, M. L., Whittam, T. S. \& Kapur, V. (2001). Complete genomic sequence of Pasteurella multocida, Pm70. Proc Natl Acad Sci U S A 98, 3460-3465.

Meats, E., Feil, E. J., Stringer, S., Cody, A. J., Goldstein, R., Kroll, J. S., Popovic, T. \& Spratt, B. G. (2003). Characterization of encapsulated and nonencapsulated Haemophilus influenzae and determination of phylogenetic relationships by multilocus sequence typing. J Clin Microbiol 41, 1623-1636.

Mutters, R., Mannheim, W. \& Bisgaard, M. (1989). Taxonomy of the group. In Pasteurella and Pasteurellosis, pp. 3-34. Edited by C. Adlam \& J. M. Rutter. London: Academic Press.

Nørskov-Lauritsen, N., Christensen, H., Okkels, H., Kilian, M. \& Bruun, B. (2004). Delineation of the genus Actinobacillus by comparison of partial infB sequences. Int J Syst Evol Microbiol 54, 635-644.

Olsen, I., Dewhirst, F. E., Paster, B. J. \& Busse, H.-J. (2004). Family Pasteurellaceae Pohl 1981, 382 ${ }^{\mathrm{VP}}$. In Bergey's Manual of Systematic Bacteriology, 2nd edn. Edited by D. J. Brenner, N. R. Krieg, J. T. Staley \& G. M. Garrity. New York: Springer (in press).

Osawa, R., Rainey, F., Fujisawa, T., Lang, E., Busse, H. J., Walsh, T. P. \& Stackebrandt, E. (1995). Lonepinella koalarum gen. nov., sp. nov., a new tannin-protein complex degrading bacterium. Syst Appl Microbiol 18, 368-373.

Paster, B. J. \& Dewhirst, F. E. (1988). Phylogeny of campylobacters, wolinellas, Bacteroides gracilis, and Bacteroides ureolyticus by $16 \mathrm{~S}$ ribosomal ribonucleic acid sequencing. Int J Syst Bacteriol 38, 56-62.

Potts, T. V., Zambon, J. J. \& Genco, R. J. (1985). Reassignment of Actinobacillus actinomycetemcomitans to the genus Haemophilus as Haemophilus actinomycetemcomitans comb. nov. Int J Syst Bacteriol 35, 337-341.

Potts, T. V., Mitra, T., O'Keefe, T., Zambon, J. J. \& Genco, R. J. (1986). Relationships among isolates of oral haemophili as determined by DNA-DNA hybridization. Arch Microbiol 145, 136-141.

Selander, R. K., Caugant, D. A., Ochman, H., Musser, J. M., Gilmour, M. N. \& Whittam, T. S. (1986). Methods of multilocus enzyme electrophoresis for bacterial population genetics and systematics. Appl Environ Microbiol 51, 873-884.

Wayne, L. G., Brenner, D. J., Colwell, R. R. \& 9 other authors (1987). International Committee on Systematic Bacteriology. Report of the ad hoc committee on reconciliation of approaches to bacterial systematics. Int J Syst Bacteriol 37, 463-464. 